\title{
Disparate E-cadherin mutations in LCIS and associated invasive breast carcinomas
}

\author{
K M Rieger-Christ`, J A Pezza ${ }^{\star}$ J M Dugan, J W Braasch, K S Hughes, I C Summerhayes
}

^These authors were equal contributors to this work

\begin{abstract}
Aims-The relation between lobular carcinoma in situ (LCIS) and invasive breast cancer is unresolved. In an attempt to establish whether LCIS is a precursor of invasive cancer the mutational status and the expression of E-cadherin was analysed in LCIS and associated invasive breast carcinoma in 23 patients.
\end{abstract}

Methods-Foci of LCIS and associated invasive carcinoma were individually microdissected from tissue from 23 patients. Exons 4-16 of the E-cadherin gene were analysed using single strand conformation polymorphism (SSCP); protein expression and the localisation of $E$-cadherin and $\beta$-catenin were assessed with the use of immunohistochemistry.

Results-Immunohistochemistry revealed a lack of expression of $E$-cadherin and $\beta$-catenin in most LCIS samples and invasive foci. In all but four cases, the staining pattern was identical in the LCIS and associated invasive areas. When E-cadherin was absent, $\beta$-catenin was also undetected, suggesting a lack of expression of alternative classic cadherin members in these lesions. Coincident E-cadherin mutations in LCIS and associated invasive carcinoma were not identified in this series of patients. However, mutational analysis of E-cadherin in multiple foci of carcinoma in situ surrounding an invasive lesion provided evidence to support ductal carcinoma in situ as a precursor of invasive ductal carcinoma.

Conclusion-These data support the hypothesis that LCIS is not a precursor of invasive breast carcinoma but a marker of increased risk of developing invasive disease.

(F Clin Pathol: Mol Pathol 2001;54:91-97)

Keywords: lobular carcinoma in situ; breast; E-cadherin; infiltrating lobular carcinoma

Department of Pathology, Lahey Clinic, 41 Mall Road Burlington, MA 01805, USA

J M Dugan

Department of General Surgery, Lahey Clinic K S Hughes

Correspondence to: Dr Rieger-Christ

Kimberly.R.Christ@1ahey.org

Accepted for publication 6 December 2000 carcinoma over the next 15-20 years, with an almost equal risk in the ipsilateral and contralateral breast. ${ }^{1-3}$ Moreover, approximately 50\% of these invasive carcinomas will be of the ductal type. ${ }^{2}{ }^{4}$ To date, it is not possible to predict which patients with LCIS will subsequently develop an invasive cancer.

Loss of heterozygosity ( $\mathrm{LOH}$ ) studies of primary breast tumours have identified deletions at the chromosomal region $16 \mathrm{q} 22.1$ in $50 \%$ of informative breast cancer cases, suggesting the presence of a possible tumour suppressor gene. ${ }^{5-8}$ E-cadherin, a transmembrane protein responsible for cell-cell adhesion, is localised in this region and has been implicated because alterations in E-cadherin have been found in various breast lesions. For instance, reduced E-cadherin expression has been recorded in approximately $50 \%$ of infiltrating ductal carcinomas (IDCs), and complete loss of E-cadherin has been demonstrated in most infiltrating lobular carcinomas (ILCs). ${ }^{9-13}$ The molecular basis for this loss of expression appears to be different in lobular and ductal lesions. In a study by Berx et $a l,{ }^{14}$ truncation mutations were recorded in four of seven invasive lobular breast cancers in which a loss of the wild-type E-cadherin allele and a lack of detectable E-cadherin protein were demonstrated. Interestingly, they detected no mutations in a series of 42 infiltrative ductal and medullary carcinomas.

The biological nature of LCIS and its relation to invasive carcinoma are unclear because molecular analysis studies are few and limited by the small size of the lesion. One hypothesis considers LCIS solely as a risk indicator for invasive disease. ${ }^{15}{ }^{16}$ In support of this are the results from comparative genomic hybridisation analyses of LCIS and invasive cancer, which showed some similarities at the chromosomal level, although there were also significant differences. ${ }^{17}$ The analysis of LCIS cases that subsequently developed invasive carcinoma showed that a linear accumulation of chromosomal gains and losses did not account for progression from non-invasive to invasive disease in all cases. An alternative hypothesis states that LCIS cells are intermediates in progression to invasive cancer. ${ }^{4}$ De Leeuw and colleagues demonstrated identical E-cadherin staining patterns in associated LCIS and invasive lobular cancers, implying that the former was the precursor of the latter. ${ }^{18}$ In a subsequent report, in two cases this same group demonstrated the presence of the same truncating mutation in the LCIS component and the associated ILC, supportive of the hypothesis that LCIS is a preneoplastic lesion capable of progression to malignancy. ${ }^{19}$ 
Table 1 Primers for single strand conformation polymorphism analysis

\begin{tabular}{|c|c|c|c|}
\hline Exon & Primer sequences & Size $(b p)$ & $\begin{array}{l}\text { Annealing } \\
\text { temperature } \\
\left({ }^{\circ} \mathrm{C}\right)\end{array}$ \\
\hline $4 \mathrm{~F}$ & 5'-TTCCTTTTAGGCCTCCGTTT-3' & 155 & $55^{\circ} \mathrm{C}$ \\
\hline $4 \mathrm{R}$ & 5'-CCTGAACCAGGTTTTTAGGAAA-3' & & \\
\hline $5 \mathrm{~F}$ & 5'-TTGTCTTCAGATCAAATCCAACA-3' & 165 & $54^{\circ} \mathrm{C}$ \\
\hline $5 \mathrm{R}$ & 5'-GTGTATGTGGCAATGCGTTC-3' & & \\
\hline $6 \mathrm{~F}$ & 5'-TTGGTTCTTTCAGCTCTTCTCTC-3' & 169 & $55^{\circ} \mathrm{C}$ \\
\hline $6 \mathrm{R}$ & 5'-GGATATACCTGGAAGAGCACCTT-3' & & \\
\hline $7 \mathrm{~F}$ & 5'-CCAGGAACCTCTGTGATGGA-3' & 163 & $55^{\circ} \mathrm{C}$ \\
\hline $7 \mathrm{R}$ & 5'-TGGTGACCACACTGATGACTC-3' & & \\
\hline $8 \mathrm{~F}$ & 5'-TTTCCCTACGTATACCCTGGTG-3' & 134 & $55^{\circ} \mathrm{C}$ \\
\hline $8 \mathrm{R}$ & 5'-GAATTACCGTGGTGGGATTG-3' & & \\
\hline $9 \mathrm{~F}$ & 5'-TGCAGTACAAGGGTCAGGTG-3' & 198 & $55^{\circ} \mathrm{C}$ \\
\hline $9 \mathrm{R}$ & 5'-CCATACAAACCTTTGCTGTTTTC-3' & & \\
\hline $10 \mathrm{~A} \mathrm{~F}$ & 5'-TCTGCTCTCTAGGGCTTGGA-3' & 136 & $54^{\circ} \mathrm{C}$ \\
\hline $10 \mathrm{~A} \mathrm{R}$ & 5'-CATTCACATCCAGCACATCC-3' & & \\
\hline $10 \mathrm{~B} \mathrm{~F}$ & 5'-GGATGTGCTGGATGTGAATG-3' & 150 & $54^{\circ} \mathrm{C}$ \\
\hline $10 \mathrm{~B} \mathrm{R}$ & 5'-CACACTTACGTTATTTTCTGTTCCA-3' & & \\
\hline $11 \mathrm{~F}$ & 5'-CGTTCAGATATCGGATTTGG-3' & 163 & $55^{\circ} \mathrm{C}$ \\
\hline $11 \mathrm{R}$ & 5'-GCCCССТTACCATTGTCTGT-3' & & \\
\hline $12 \mathrm{~A} \mathrm{~F}$ & 5'-TTTCTCTTAGGTTCTCCAGTTGC-3' & 131 & $54^{\circ} \mathrm{C}$ \\
\hline $12 \mathrm{~A} \mathrm{R}$ & 5'-ACCTGAGGCTTTGGATTCCT-3' & & \\
\hline $12 \mathrm{~B} \mathrm{~F}$ & 5'-GAGAGGAATCCAAAGCCTCA-3' & 135 & $52^{\circ} \mathrm{C}$ \\
\hline $12 \mathrm{~B} \mathrm{R}$ & 5'-GTACCCACTTGGGTCGTTGT-3' & & \\
\hline $13 \mathrm{~A} \mathrm{~F}$ & 5'-GCTTTCTCCAGCCCAAGAAT-3' & 142 & $54^{\circ} \mathrm{C}$ \\
\hline $13 \mathrm{~A} \mathrm{R}$ & 5'-TTCACAGTCACACACGCTGA-3' & & \\
\hline $13 \mathrm{~B} \mathrm{~F}$ & 5'-TCAGCGTGTGTGACTGTGAA-3' & 113 & $52^{\circ} \mathrm{C}$ \\
\hline 13B R & 5'-CAAAGCAAGAATTCCTCCAAG-3' & & \\
\hline $14 \mathrm{~F}$ & 5'-CCACCATCCCAGTTCTGATT-3' & 152 & $55^{\circ} \mathrm{C}$ \\
\hline $14 \mathrm{R}$ & 5'-AAAACCCACCTGGTCСТСТT-3' & & \\
\hline $15 \mathrm{~F}$ & 5'-TTTTTCTCCAAAGGACTTTGACT-3' & 163 & $55^{\circ} \mathrm{C}$ \\
\hline $15 \mathrm{R}$ & 5'-ACTTACTTCATСAATAAAATTTCСAAT-3' & & \\
\hline $16 \mathrm{~A} \mathrm{~F}$ & 5'-ССTTCTTCTTGAGAATCTGAAAGC-3' & 172 & $55^{\circ} \mathrm{C}$ \\
\hline $16 \mathrm{~A} \mathrm{R}$ & 5'-GCCCCATTCGTTCAAGTAGT-3' & & \\
\hline $16 \mathrm{~B} \mathrm{~F}$ & 5'-TTCCGAAGCTGCTAGTCTGAG-3' & 184 & $55^{\circ} \mathrm{C}$ \\
\hline $16 \mathrm{~B} \mathrm{R}$ & 5'-ATTTCTGCATTTCCCAGCAC-3' & & \\
\hline
\end{tabular}

$\mathrm{F}$, forward primer; $\mathrm{R}$, reverse primer.

In our study, we have extended the analysis of E-cadherin in LCIS and compared the mutational events recorded with those in associated invasive carcinomas. In the 23 patients studied we did not identify a single case in which the LCIS and invasive lesion displayed the same E-cadherin mutation.

\section{Materials and methods}

TISSUE SAMPLES

Twenty three breast tumour samples were obtained from individuals with invasive breast cancer who underwent surgery at the Lahey Clinic, between 1990 and 1999. Tissue was stored as formalin fixed, paraffin wax embedded blocks at room temperature. Of the 23 cases of invasive breast cancer, 14 were lobular and nine were ductal carcinomas. All cases had accompanying LCIS.

MICRODISSECTION AND DNA EXTRACTION

In each case, a $5 \mu \mathrm{m}$ slide was cut, dewaxed, and haematoxylin and eosin (H\&E) stained for orientation. Five subsequent slides from the same block were cut at $10 \mu \mathrm{m}$, dewaxed, and $\mathrm{H} \& \mathrm{E}$ stained for microdissection using a 23 gauge needle. All slides were reviewed by a staff pathologist (JMD) who gave particular attention to selecting pure LCIS lesions. Tissue from LCIS and invasive foci was microdissected and immediately placed in $125 \mu$ lysis buffer $(10 \mathrm{mM}$ Tris/ $\mathrm{HCl}$ at $\mathrm{pH} 8.3,0.37 \%$ $\mathrm{KCl}, 2.5 \mathrm{mM} \mathrm{MgCl}_{2}, 0.45 \%$ Tween-20, and $0.5 \mathrm{mg} / \mathrm{ml}$ proteinase $\mathrm{K}$ ) then incubated at $55^{\circ} \mathrm{C}$ for two hours with shaking. After incubation at $95^{\circ} \mathrm{C}$ for 15 minutes, $2 \mathrm{mM}$ EDTA was added to the sample, which was stored at $4^{\circ} \mathrm{C}$. Additional associated foci including LCIS, ductal carcinoma in situ (DCIS), and foci with morphological features of both, termed foci of intermediate morphology, were dissected from the paraffin wax blocks of two other patients (22 and 23). Microdissected specimens contained $>90 \%$ target cells from CIS lesions and $>75 \%$ from invasive lesions.

POLYMERASE CHAIN REACTION (PCR)

Table 1 shows the oligonucleotide primer sequences for amplification of the translated portion of the E-cadherin gene (exons 4-16). Overlapping primers were designed for exons $10,12,13$, and 16 to decrease the size of the PCR product for single strand conformation polymorphism (SSCP) analysis. PCR amplification was carried out in a $25 \mu \mathrm{l}$ volume containing $5 \mu \mathrm{l}$ of extracted DNA, $1 \times$ PCR buffer containing $15 \mathrm{mM} \mathrm{MgCl}, 200 \mu \mathrm{M}$ each of dATP, dGTP, and dTTP, $120 \mu \mathrm{M}$ dCTP, 1 unit of Taq DNA polymerase (Perkin Elmer Gene Amp, Foster City, California, USA), $0.4 \mu \mathrm{M}$ of forward and reverse primers, and $2.0 \mu \mathrm{Ci}$ of $\left[\gamma_{-}{ }^{32} \mathrm{P}\right] \mathrm{dCTP}$ (Amersham, Arlington Heights, Illinois, USA). After an initial denaturation at $95^{\circ} \mathrm{C}$ for five minutes, 40 cycles at $95^{\circ} \mathrm{C}$ for 60 seconds, $52^{\circ} \mathrm{C}$ (exons $12 \mathrm{~B}$ and $13 \mathrm{~B}$ ), or $54^{\circ} \mathrm{C}$ (exons $5,10 \mathrm{~A}, 10 \mathrm{~B}$, $12 \mathrm{~A}$, and $13 \mathrm{~A}$ ), or $55^{\circ} \mathrm{C}$ (exons $4,6-9,11$, 14-16B) for 60 seconds, and $72^{\circ} \mathrm{C}$ for $60 \mathrm{sec}-$ onds were performed. The last cycle was followed by a 10 minute extension at $72^{\circ} \mathrm{C}$.

SSCP ANALYSIS

Aliquots of $4 \mu \mathrm{l}$ of the PCR product were mixed with $16 \mu$ of stop solution (95\% formamide, $20 \mathrm{mM}$ EDTA, $0.05 \%$ bromophenol blue, and $0.05 \%$ xylene cyanol FF), heat denatured at $95^{\circ} \mathrm{C}$ for five minutes, and $3 \mu \mathrm{l}$ aliquots were rapidly loaded on to non-denaturing polyacrylamide gels. All samples were run under two different gel conditions: (1) $6 \%$ acrylamide and $10 \%$ glycerol run at room temperature with a cooling fan at $30 \mathrm{~W}$; and (2) $8 \%$ acrylamide with no glycerol run at $4^{\circ} \mathrm{C}$ and $30 \mathrm{~W}$. The gels were dried at $80^{\circ} \mathrm{C}$ and autoradiographed using Kodak BioMax film (Eastman Kodak, Rochester, New York, USA) for 24 to 96 hours. The tumour was scored as having a mutation if an abnormal SSCP pattern was detected in repeat experiments involving separate PCR reactions. We have shown that a mutation can be identified in SSCP when present in $5 \%$ of the DNA analysed. ${ }^{20}$

DNA SEQUENCING

Aberrantly migrating DNA fragments were excised from the gel and extracted after boiling in water for 15 minutes. DNA was ethanol precipitated in glycogen and used for PCR as described above. An aliquot of $4 \mu \mathrm{l}$ of the PCR product was subcloned and used in the transformation of competent cells provided in the TA cloning kit (InVitrogen, San Diego, California, USA), according to the manufacturer's instructions. Colonies containing PCR product were grown overnight in Luria-Bertani medium ( $1 \%$ tryptone wt/vol, $0.5 \%$ yeast extract wt/vol, $0.5 \% \mathrm{NaCl} w \mathrm{wt} / \mathrm{vol}$, and $10 \mathrm{mM}$ $\mathrm{NaOH}$ ), and the plasmids were extracted. 

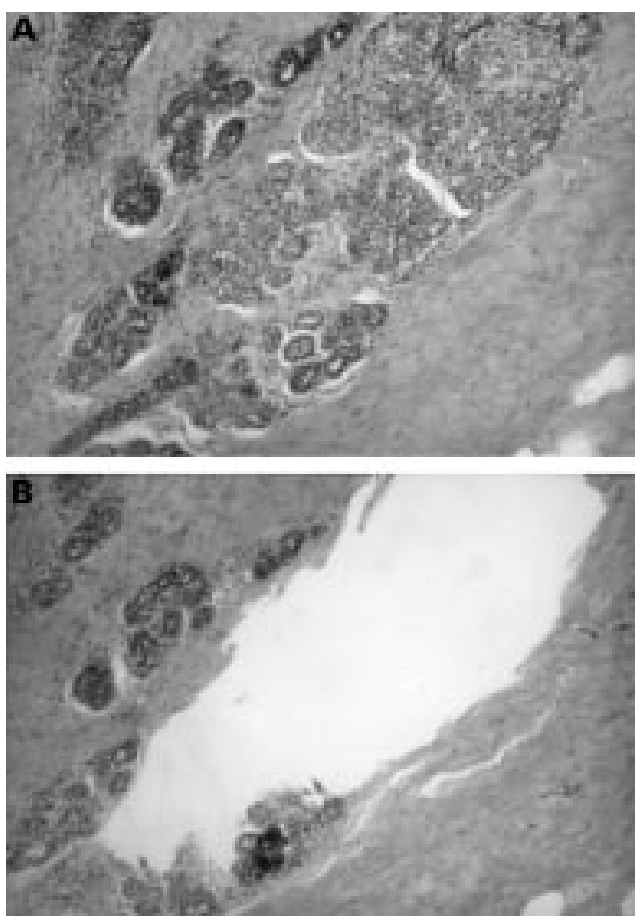

Figure 1 Lobular carcinoma in situ lesion $(A)$ before and (B) after microdissection.

Sequencing was performed according to the dideoxy chain termination method using a Sequenase Version 2.0 Kit (USB, Cleveland, Ohio, USA), according to the manufacturer's instructions. Samples were loaded on to a $6 \%$ denaturing polyacrylamide gel containing $7 \mathrm{M}$ urea and run between $45^{\circ} \mathrm{C}$ and $50^{\circ} \mathrm{C}$. Dried gels were autoradiographed for 16 to 24 hours.

\section{IMMUNOHISTOCHEMISTRY}

Standard immunohistochemical detection was performed on $5 \mu \mathrm{m}$ sections of formalin fixed, paraffin wax embedded specimens after antigen retrieval. Samples were dewaxed and heated in a $10 \mathrm{mM}$ citric acid monophosphate buffer ( $\mathrm{pH} \mathrm{6.0)}$ ) for 30 minutes in a $1.35 \mathrm{~kW}$ microwave oven at high power. To minimise the evaporation of buffer during heating, the tissue slides were microwaved in a non-metallic kitchen pressure cooker (Nordicware, Minneapolis, USA). Immunohistochemical staining was performed with an automated immunohistochemical processor (Model 320; Ventana Medical Systems, Tucson, Arizona, USA). Primary antibodies used were HECD-1 (1/500; Zymed, San Francisco, California, USA) and $\beta$-catenin (1/500; Transduction Laboratories, San Diego, California, USA). Slides were then dehydrated and mounted with Permaslip

Table 2 Mutational status of E-cadherin in lobular carcinoma in situ samples

\begin{tabular}{llllll}
\hline Patient & Exon & $b p$ & Codon & Mutation & Predicted effect \\
\hline 5 & 7 & 308 & 1016 & GAT $\rightarrow$ AAT & Asp $\rightarrow$ Asn \\
9 & 14 & 740 & 2218 & CCC $\rightarrow$ TCC & Pro $\rightarrow$ Ser \\
10 & 6 & $262-265$ & $786-794$ & 9 bp deletion & Early stop \\
11 & 15 & 774 & 2321 & AGG $\rightarrow$ AAG & Arg $\rightarrow$ Lys \\
13 & 7 & 286 & 856 & GCC $\rightarrow$ ACC & Ala $\rightarrow$ Thr \\
& & 298 & 893 & GCC $\rightarrow$ GAC & Ala $\rightarrow$ Asp \\
14 & 6 & 255 & 763 & CAG $\rightarrow$ TAG & Gln $\rightarrow$ Stop \\
16 & 6 & 245 & 734 & CCA $\rightarrow$ CTA & Pro $\rightarrow$ Leu \\
& & 257 & 770 & GAC $\rightarrow$ GGC & Asp $\rightarrow$ Gly \\
21 & 16 & 851 & 2552 & TCA $\rightarrow$ TTA & Ser $\rightarrow$ Leu \\
\hline
\end{tabular}

(Alban Scientific, St Louis, USA). Normal epithelial tissue found within sections served as an internal control. The status of E-cadherin and $\beta$-catenin was assessed in a coded manner by a staff pathologist without knowledge of the clinical or pathological features of the case.

\section{Results}

We initially analysed E-cadherin gene and protein expression in a series of breast lesions from 21 patients. In each case, LCIS and the associated carcinoma were identified by the pathologist. Tissue was microdissected from sections and the extracted DNA was used for molecular analysis of the E-cadherin gene. Subsequent sections were cut and processed for immunohistochemistry.

MOLECULAR ANALYSIS OF THE E-CADHERIN GENE Five $10 \mu \mathrm{m}$ thick sections were cut from paraffin wax embedded blocks and the areas corresponding to the foci of LCIS and tumour were microdissected (fig 1) and processed for DNA extraction. Seventeen primer sets were used to amplify the 13 coding exons of E-cadherin (table 1) and samples were analysed by PCR-SSCP. Aberrantly migrating bands were identified in eight of the 21 LCIS lesions analysed, involving exons 6, 7, 14, 15, and 16 . These bands were excised from the gel and sequenced by means of a TA cloning step. Nine of the ten bands analysed revealed point mutations and one a deletion (table 2). Two of these mutations resulted in a premature stop codon.

The analysis of the E-cadherin gene from the invasive region of tumours was limited to those in which a mutation had been found in the associated LCIS. SSCP and sequence analysis was restricted to the exon harbouring a mutation in the neighbouring LCIS. In only two of eight cases were aberrantly migrating bands detected in which sequencing revealed the presence of mutations in both of the samples. In patient 21 , a point mutation was detected in exon 16 changing a glutamic acid to a lysine, an event not found in the associated LCIS. In patient 16, two point mutations were recorded in exon 6, changing an alanine to a valine and the other resulting in an early stop codon; the same mutations were not found in the associated LCIS in this patient. Analysis of the status of the E-cadherin gene in LCIS and the associated invasive tumour was performed in multiple repeat experiments.

A review of the histology of the invasive areas revealed that 12 of the invasive tumour areas were ILC and nine were IDC. In most of these lesions loss of E-cadherin expression was recorded by immunohistochemistry (table 3) and yet no coincident E-cadherin mutations were found in LCIS and the associated invasive lesion in the eight cases studied. We therefore selected a subgroup of tissues, comprising five of the ILC samples in which no molecular alteration of E-cadherin was detected in the LCIS component. In each case we analysed the entire E-cadherin gene using PCR-SSCP. Aberrant bands were recorded in four of the 
Table 3 Expression of E-cadherin and $\beta$-catenin in lobular carcinoma in situ (LCIS) and adjacent invasive areas

\begin{tabular}{|c|c|c|c|c|c|}
\hline \multirow[b]{2}{*}{ Patient } & \multicolumn{2}{|l|}{ LCIS } & \multicolumn{3}{|l|}{ Invasive } \\
\hline & E-cadherin & $\beta$-Catenin & E-cadherin & $\beta$-Catenin & Histology \\
\hline 1 & + & + & + & + & ILC \\
\hline 2 & ND & ND & + & + & IDC \\
\hline 3 & - & - & - & - & IDC \\
\hline 4 & - & ND & - & - & ILC \\
\hline 5 & - & - & + & + & IDC \\
\hline 6 & $\mathrm{H}$ & - & $\mathrm{H}$ & + & IDC \\
\hline 7 & ND & ND & ND & ND & ILC \\
\hline 8 & - & - & - & - & ILC \\
\hline 9 & ND & - & - & - & ILC \\
\hline 10 & ND & ND & $\mathrm{H}$ & ND & ILC \\
\hline 11 & - & - & ND & ND & ILC \\
\hline 12 & - & - & - & - & IDC \\
\hline 13 & - & ND & $\mathrm{H}$ & + & IDC \\
\hline 14 & ND & - & ND & - & IDC \\
\hline 15 & $\mathrm{H}$ & - & + & - & IDC \\
\hline 16 & - & - & - & - & ILC \\
\hline 17 & - & - & $\mathrm{H}$ & $\mathrm{H}$ & IDC \\
\hline 18 & - & - & - & - & ILC \\
\hline 19 & - & - & - & - & ILC \\
\hline 20 & - & - & - & - & ILC \\
\hline 21 & - & - & - & - & ILC \\
\hline
\end{tabular}

Staining: +, membranous staining; -, no detectable membranous staining; $\mathrm{H}$, limited membranous staining.

IDC, infiltrating ductal carcinoma; ILC, infiltrating lobular carcinoma; ND, not determined owing to lack of tissue availability.
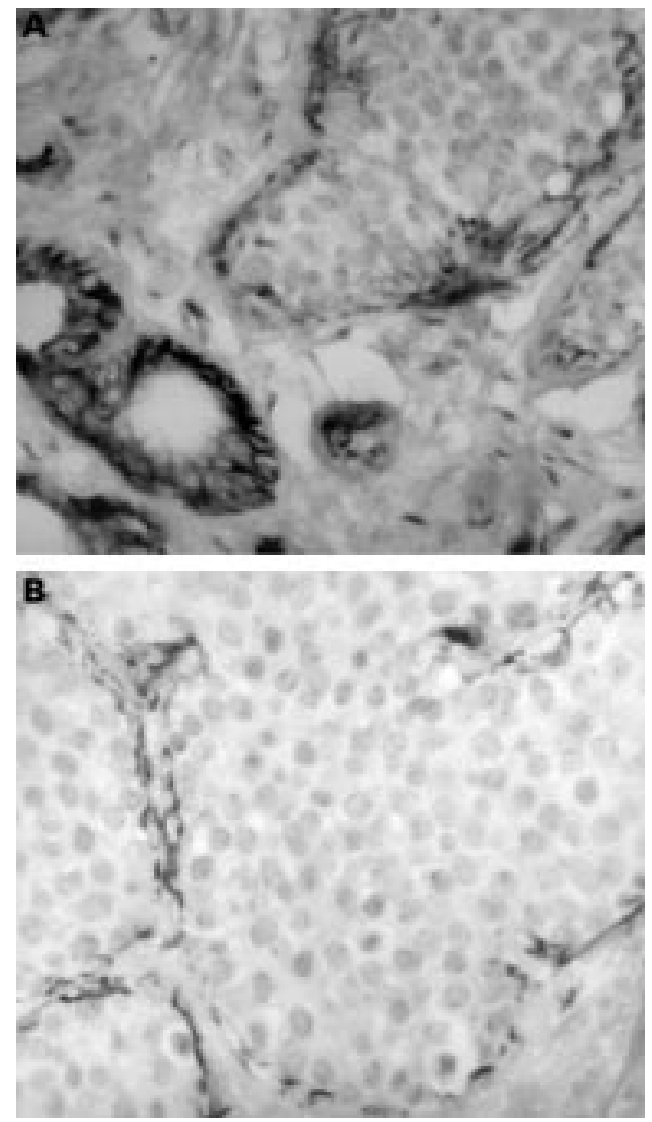

Figure 2 (A) Immunohistochemical staining of breast tissue showing the membranous location of E-cadherin in normal glands adjacent to carcinoma in situ (CIS) where no staining was found. (B) Immunostaining in a CIS lesion showing $\beta$-catenin localised to myoepithelial cells. No $\beta$-catenin was detected in cells of the CIS lesion, which also displayed loss of E-cadherin expression. normal ducts and lobules served as an internal control in sections. Because our first priority was the molecular analysis of E-cadherin, not all cases displayed the continued presence of LCIS after the harvesting of sections for microdissection. These cases were necessarily excluded from this part of the study. In addition, it should be noted that not all LCIS lesions were harvested from the same section harbouring the invasive lesion, but existed in an alternative paraffin wax block of the excised tissue. In these cases, the microdissected LCIS foci represented the sole LCIS lesions associated with the excised carcinoma; hence, the spatial relation between the two is not clear. Table 3 summarises the immunohistochemistry results.

Loss or heterogeneous expression of E-cadherin was recorded in 13 of 16 and two of 16 LCIS lesions, respectively. These results are consistent with previous reports of a high frequency of loss of E-cadherin expression associated with LCIS. ${ }^{11-1421}$ In our study, membrane associated E-cadherin was recorded in only one of the 16 foci of LCIS analysed.

Loss of E-cadherin expression in different lesions does not necessarily indicate a complete absence of cadherins because recent work has shown continued or aberrant expression of alternative cadherin family members in neoplastic progression..$^{22-27}$ In these circumstances, $\beta$-catenin maintains its membrane localisation associated with the alternative classic cadherin member expressed. Immunostaining of LCIS with $\beta$-catenin revealed an absence of expression of this catenin in all cells found to lack E-cadherin expression, confirmed by the staining of $\beta$-catenin in myoepithelial cells surrounding LCIS islands in sections (fig 2). Immunohistochemical analysis of E-cadherin was also performed on the invasive tumour areas associated with the aforementioned LCIS lesions. Of the 18 invasive regions that could be evaluated for E-cadherin, 10 were negative, four displayed heterogeneous expression, and four samples showed membranous E-cadherin throughout the tumour. In most cases (12 of 16), the expression and localisation of E-cadherin in the LCIS and invasive regions were indistinguishable. However, there were four cases (patients $5,13,15,17$ ) in which the E-cadherin staining pattern differed between the LCIS focus displayed heterogeneous staining, whereas the invasive lesion exhibited membranous staining throughout. In two cases, E-cadherin expression was not detected in the focus of LCIS, whereas the invasive area exhibited heterogeneous staining. In the last case, membranous E-cadherin was observed throughout the tumour but was absent in the LCIS lesion. the LCIS and invasive areas. In one of these, 


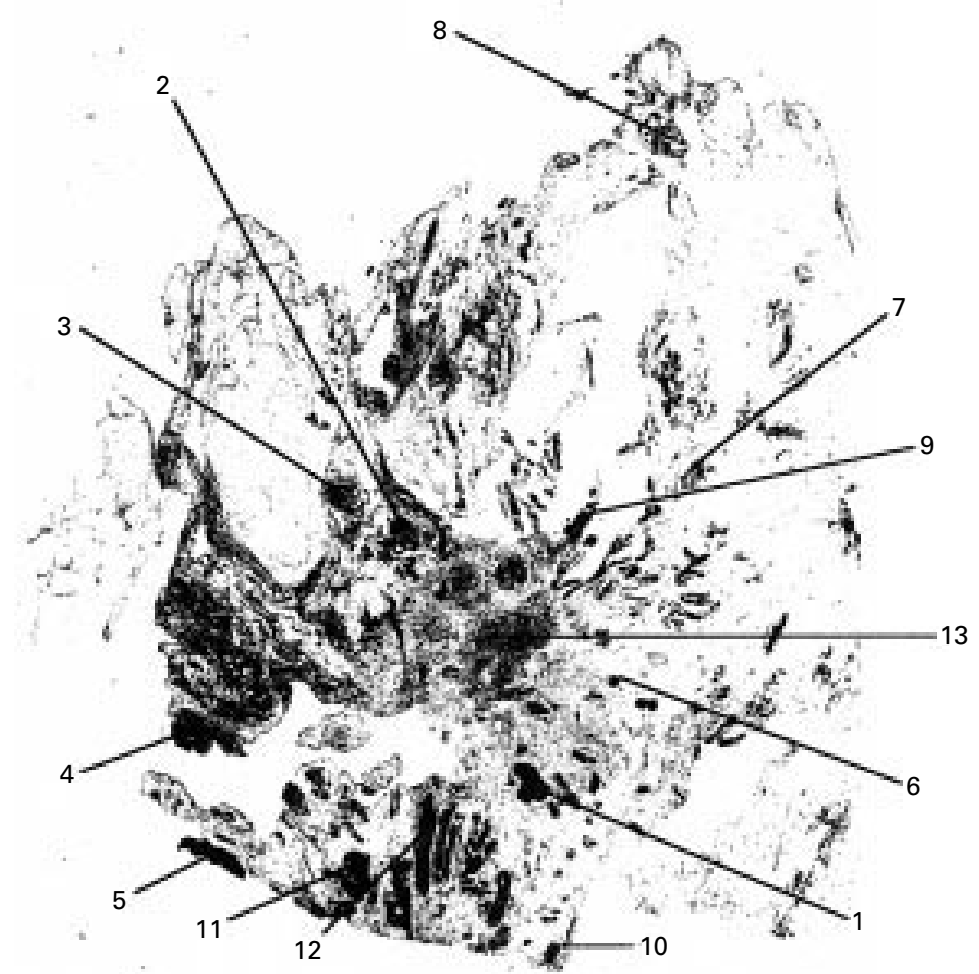

Figure 3 A single section from patient 22 showing the localisation of different microdissected lesions relative to the invasive carcinoma (focus 13). Foci 1, 2, 5, 11, and 12 were identified as ductal carcinoma in situ (DCIS); foci 3, 6, and 8 were identified as lobular carcinoma in situ (LCIS) and foci 4, 7, 9, and 10 were identified as intermediate morphology. Focus 13 represents an area of infiltrating ductal carcinoma.

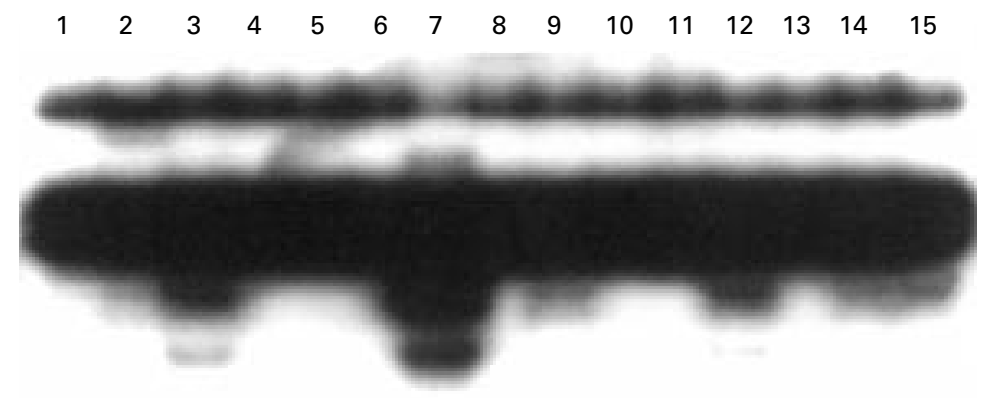

Figure 4 Single strand conformation polymorphism analysis of exon 6 of the E-cadherin gene from patient 22. Lane 1, negative control; lanes 2 and 15, infiltrating ductal carcinoma focus 13; lanes 3-14, foci 1-12, respectively. Note the aberrantly migrating band in lanes $2,3,7,9,12,14$, and 15 .

Table 4 Mutational analysis of multiple carcinoma in situ lesions surrounding an invasive ductal carcinoma (patient 22)

\begin{tabular}{lllllll}
\hline Lesion & Pathology & Exon & Mutation & $b p$ & Codon & Result \\
\hline 1 & DCIS & 6 & 9 bp del., insert T & $786-794$ & $262-265$ & Early stop \\
2 & DCIS & & & & & \\
3 & LCIS & & & & & \\
4 & Intermediate & & & & \\
5 & DCIS & 6 & 9 bp del., insert T & $786-794$ & $262-265$ & Early stop \\
6 & LCIS & & & & & \\
7 & Intermediate & 6 & 9 bp del., insert T & $786-794$ & $262-265$ & Early stop \\
8 & LCIS & & & & & \\
9 & Intermediate & & & & \\
10 & Intermediate & 6 & 9 bp del., insert T & $786-794$ & $262-265$ & Early stop \\
11 & DCIS & & & & & \\
12 & DCIS & 6 & CCC $\rightarrow$ CTC & 779 & 260 & Pro $\rightarrow$ Leu \\
13 & IDC & 6 & 9 bp del., insert T & $786-794$ & $262-265$ & $\begin{array}{l}\text { Early stop } \\
\text { Early stop }\end{array}$
\end{tabular}

Pathology: DCIS, ductal carcinoma in situ; IDC, infiltrating ductal carcinoma; Intermediate, morphological features of LCIS and DCIS; LCIS, lobular carcinoma in situ. del., deletion.
ANALYSIS OF MULTIPLE CIS LESIONS

SURROUNDING INVASIVE CARCINOMA

Despite the fact that we had analysed LCIS lesions associated with invasive carcinomas, the three dimensional spatial relation between these two is not always known, even when they exist in the same section. It is possible that an alternative LCIS lesion, not apparent in the section, is the true precursor of the invasive lesion in these cases. In essence, we may be studying the wrong LCIS lesion if changes are multifocal in the breast. Because of the potential multifocality of breast lesions we selected sections from two patients in whom multiple morphologically distinct CIS foci presented in close proximity to the invasive area. In both cases, these foci could be identified by the pathologists and were distributed such that they could be cleanly microdissected, enabling the isolation of a pure population of cells.

Sections from these two patients were stained for E-cadherin and $\beta$-catenin using the conditions outlined above. Once again, normal ducts exhibited membranous staining for both E-cadherin and $\beta$-catenin. In both patients, neither the invasive area nor any of the surrounding CIS foci, which consisted of both LCIS and DCIS, exhibited staining for E-cadherin or $\beta$-catenin (data not shown).

MUTATION ANALYSIS OF E-CADHERIN

To prevent bias, the invasive area and surrounding CIS foci were microdissected without knowledge of their pathology status. The E-cadherin gene was analysed by SSCP, followed by sequencing. After the molecular analysis, pathological assessment of lesions from patient 22 revealed that of the 12 islands microdissected, five were pure DCIS, three were pure LCIS, and four were of an intermediate morphology. The invasive focus in patient 22 was determined to be an invasive ductal carcinoma. Figure 3 shows the localisation of CIS relative to the invasive ductal carcinoma in these sections. SSCP analysis identified aberrant bands with identical migration patterns associated with exon 6 in multiple samples (fig 4). Excision and sequencing of each of these products revealed the same mutation in five CIS foci and the invasive ductal component (table 4). Seven CIS foci displayed no detectable aberrantly migrating bands in exon 6, despite the loss of expression of E-cadherin, as determined by immunohistochemistry. Interestingly, all five foci harbouring the same mutation as the invasive lesion were either pure DCIS or of an intermediate morphology. None of the pure LCIS islands was found to harbour a mutation in this analysis.

In a second case (patient 23), 10 morphologically distinct islands were microdissected in addition to the invasive lesion, which was identified as an invasive lobular carcinoma. Of the microdissected tissue, seven foci were identified as DCIS and three as pure LCIS, all of which displayed loss of E-cadherin expression by immunostaining. The point mutation identified in the invasive lobular component was not detected in the foci analysed. 


\section{Discussion}

Genetic studies have supported a model for breast carcinogenesis whereby most ductal tumours follow a progression from atypical hyperplasia to in situ carcinoma and eventually to invasive carcinoma. ${ }^{28}{ }^{29}$ Although this is generally accepted for DCIS, controversy remains about LCIS as a precursor of invasive disease. One hypothesis is that LCIS is only a marker of risk for future disease. ${ }^{15} 16$ This idea is supported by several arguments. First, foci of LCIS associated with microinvasion are infrequently reported..$^{31}$ In contrast, microinvasion associated with DCIS is well described. Second, a linear accumulation of chromosomal gains and losses cannot always account for progression from non-invasive to invasive disease. ${ }^{17}$ Third, $50 \%$ of subsequent invasive lesions that develop occur in the contralateral breast and can be either lobular or ductal tumours. ${ }^{1-3}$ Whether LCIS and DCIS have the same cell of origin remains an area of controversy within this field. Evidence for LCIS being a precursor of lobular carcinoma comes mainly from molecular analysis, where the same E-cadherin mutation in LCIS and the associated carcinoma has been reported in a small number of cases. ${ }^{19}$

The goal of our study was to analyse E-cadherin expression in an extended series of patients in LCIS and the associated invasive carcinoma to establish the relation between these two lesions. Immunohistochemical analysis revealed loss or heterogeneous E-cadherin expression in 15 of 16 LCIS lesions, confirming previous reports of a high frequency of loss of E-cadherin associated with LCIS. ${ }^{11-14}$ Identical staining patterns were recorded in 12 of 16 invasive carcinomas associated with LCIS in excised tissue. Only four invasive tumours showed a different pattern of E-cadherin staining to their corresponding LCIS focus. These observations were consistent with the idea that LCIS is a precursor of invasive cancer in these cases. Although many regions of DCIS retained membranous E-cadherin staining, we found several instances where foci of DCIS displayed loss of E-cadherin expression.

Recently, numerous studies have shown that the loss of E-cadherin in tumours is not always indicative of a total absence of cadherin expression because alternative cadherin members can be found. ${ }^{22-27}$ For instance, our group has identified the expression of both $\mathrm{P}$-cadherin and $\mathrm{N}$-cadherin in bladder tumours in the absence of E-cadherin expression. ${ }^{27}$ In such cases, $\beta$-catenin retains a membranous localisation associated with the alternative classic cadherins expressed. For this reason, we assessed $\beta$-catenin in all breast lesions to determine the possibility of a similar event in compromised breast tissue. In all cases where E-cadherin was undetected, $\beta$-catenin was also absent by immunohistochemistry. The continued presence of membranous $\beta$-catenin in myoepithelial cells surrounding LCIS and in stromal cells and blood vessels associated with invasive lesions confirmed the loss of expression of $\beta$-catenin in breast lesions.
Although the immunostaining results were consistent with LCIS as a precursor of invasive cancer, the molecular analysis of E-cadherin did not support this hypothesis. Identical E-cadherin mutations were not identified in LCIS and the associated invasive lesion in the 23 patients studied. In one tumour in which multiple foci surrounding a ductal carcinoma were analysed, the same E-cadherin mutation found in the invasive component was recorded in surrounding foci of DCIS and intermediate morphology, but not LCIS. This case supports the concept that DCIS is the precursor of invasive ductal carcinoma.

Interestingly, although five foci of DCIS or intermediate morphology harboured the same mutation as the invasive area, there were numerous CIS foci in closer proximity to the tumour in which we did not detect this mutation. In addition, it is of note that DCIS and foci of intermediate morphology on the periphery of the section (fig 3; foci 5 and 7), distant from the invasive region, harbour the same mutation as the carcinoma. Of course, this might reflect the same but separate mutational event occurring in another duct generated by a common aetiological agent. Alternatively, this might represent the same duct from which the tumour was derived, a circumstance not apparent in the two dimensional field presented in a tissue section. The same approach in a second case involving an invasive lobular carcinoma revealed a lack of detectable E-cadherin staining in seven pure DCIS and three pure LCIS foci surrounding the tumour. None of the foci analysed harboured the same mutation found in the invasive lobular carcinoma.

The absence of detection of identical E-cadherin mutations in LCIS and ILC does not suggest that such mutations are uncommon in ILC. Indeed, molecular analysis of the full E-cadherin gene in five selected lobular tumours revealed the presence of a mutation in four cases. In the fifth patient, loss of E-cadherin expression may be accounted for by molecular changes occurring outside of the exon fragments analysed in our study or from gene silencing as a result of methylation. We recorded several cases of LCIS in which no E-cadherin mutation was detected in our analysis, despite a loss of E-cadherin expression, as detected by immunohistochemistry. It is interesting that multiple CIS foci, microdissected from a single section and surrounding an invasive lesion, present the same E-cadherin phenotype but show a range of genotypic changes. The multifocality of lesions in breast tissue may result from a field change associated with multiple genetic changes in this organ.

Our study focused on evaluating LCIS as a precursor of invasive breast carcinoma. In only two cases did we analyse DCIS found in the same section because the preneoplastic nature of DCIS is generally accepted. In earlier publications, progression from DCIS to ILC has been indicated, and in one model a possible transition between LCIS and DCIS has been postulated. ${ }^{32}$ However, classifying lesions as LCIS and DCIS can at times be difficult. In 
our study, we microdissected foci that were considered definitively to be LCIS, and in this way we might have excluded foci of less well defined morphology, which might have represented the precursor lesion. Although we confirm that the loss of E-cadherin expression is a frequent event associated with LCIS and invasive lesions, we have shown that the molecular events leading to this loss are not shared by the two entities. The different molecular events associated with E-cadherin in multiple foci within one section of excised breast tissue presents another tier of complexity, requiring detailed mapping of different foci to understand fully the molecular events leading to invasive breast carcinoma.

This work was supported by a grant from the Eleanor Naylor Dana Charitable Trust. J Pezza is a Robert E Wise research fellow.

1 Rosen PP, Oberman HA. Tumors of the mammary gland In: Atlas of tumor pathology. Washington, DC: Armed Forces In: Atlas of tumor pathology. Washingto

2 Millikan R, Dressler L, Geradts J, et al. The need for epidemiologic studies of in-situ carcinoma of the breast. Breast Cancer Res Treat 1995;35:65-77.

3 Ottesen GL, Graversen HP, Blichert-Toft M, et al. Lobular carcinoma in-situ of the female breast: short-term results of a prospective nationwide study. The Danish breast cancer cooperative group. Am $\mathcal{F}$ Surg Pathol 1993;17:14-21.

4 Wheeler JE, Enterline JT, Roseman JM, et al. Lobular carcinoma in situ of the breast: long term follow-up. Cancer 1974;34:554-63.

5 Cleton-Jansen AM, Noerland EW, Kuipers-Dijkshoorn NJ, et al. At least two different regions are involved in allelic imbalance on chromosome arm 16q in breast cancer. Genes Chromosomes Cancer 1994;9:1010-107.

6 Devilee P, Cornelisse CJ. Somatic genetic changes in human breast cancer. Biochim Biophys Acta 1994;1198:113-0.

7 Rodriguez E, Sreekantaiah C, Chaganti RSK. Genetic changes in epithelial solid neoplasia. Cancer Res 1994;54: changes in

8 Tsuda H, Callen DF, Fukutomi T, et al. Allele loss on chromosome 16q24.2-qter occurs frequently in breast cancers irrespectively of differences in phenotype and extent of spread. Cancer Res 1994;54:513-17.

9 Rimm D, Sinard J, Morrow J. Reduced $\alpha$-catenin and E-cadherin expression in breast cancer. Lab Invest 1995;5: 506-12.

10 Berg J, Hutter R. Breast cancer. Cancer 1995;75:257-69.

11 Gamallo C, Palacios J, Suarez A, et al. Correlation of E-cadherin expression with differentiation grade and histological type in breast carcinoma. Am f Pathol 1993;142. 987-93.

12 Moll R, Mitze M, Ferixen U, et al. Differential loss of E-cadherin expression in infiltrating ductal and lobular breast carcinomas. Am f Pathol 1993;143:1731-42.
13 Rasbridge S, Gillett C, Sampson S, et al. Epithelial (E-) and placental (P-) cadherin cell adhesion molecule expression placental (P-) cadherin cell adhesion molecule
in breast carcinoma. F Pathol 1993;169:245-50.

14 Berx G, Cleton-Jansen AM, Nollet F, et al. E-Cadherin is a tumor/invasion suppressor gene mutated in human lobular breast cancers. EMBO f 1995;14:6107-115.

15 Hutter RVP. The management of patients with lobular carcinoma in situ of the breast. Cancer 1982;53:798-802.

16 Lattes R. Lobular neoplasia (lobular carcinoma in situ) of the breast - a histological entity of controversial clinical significance. Pathol Res Pract 1980;166:415-29.

$17 \mathrm{Lu} \mathrm{Y,} \mathrm{Osin} \mathrm{P,} \mathrm{Lakhani} \mathrm{SR,} \mathrm{et} \mathrm{al.} \mathrm{Comparative} \mathrm{genomic}$ hybridization analysis of lobular carcinoma in situ and atypical lobular hyperplasia and potential roles for gains and losses of genetic material in breast neoplasia. Cancer Res 1998;58:4721-7.

18 de Leeuw WJ, Berx G, Vos CB, et al. Simultaneous loss of E-cadherin and catenins in invasive lobular breast cancer and lobular carcinoma in-situ. F Pathol 1997;183:404-11.

19 Vos CB, Cleton-Jansen AM, Berx G, et al. E-cadherin inactivation in lobular carcinoma in-situ of the breast: an early event in tumorigenesis. Br f Cancer 1997;76:1131-3.

20 Holway AH, Rieger-Christ KM, Miner WR, et al. Somatic mutation of PTEN in vulvar cancer. Clin Cancer Res 2000; 6:3228-35.

21 Berx G, Cleton-Jansen AM, Strumane K, et al. E-cadherin is inactivated in a majority of invasive human lobular breast cancers by truncation mutations throughout its extracellucancers by truncation mutations throughor

22 Gee J, Greathead P, Little AF, et al. Aberrant cadherin expression in bladder carcinoma cells. Mol Urol 1998;2:7381

23 Tomita K, van Bokhoven A, van Leenders GJ, et al. Cadherin switching in human prostate cancer progression. Cancer Res 2000;60:3650-4.

24 Bussemaker MJG, Bokohoven AV, Tomita K, et al. Complex cadherin expression in human prostate cancer cells. Int $\mathcal{F}$ Cancer 2000:85:446-50.

25 Niema MT, Prudoff RS, Johnson KR, et al. N-cadherin promotes motility in human breast cancer cells regardless of their E-cadherin expression. F Cell Biol 1999;147:631-43.

26 Hazan RB, Phillips GR, Qiao RF, et al. Exogenous expression of $\mathrm{N}$-cadherin in breast cancer cells induces cell migration, invasion, and metastasis. F Cell Biol 2000;148: 779-90.

27 Rieger-Christ KM, Cain JW, Braasch JW, et al. Expression of classic cadherin type I in urothelial neoplastic progression. Hum Pathol [In press.]

28 Dupont WD, Page DL. Risk factors for breast cancer in women with proliferative breast disease. $N$ Engl f Med 1985;312:146-51.

29 Page DL, Dupont WD, Rogers LW, et al. Atypical hyperplastic lesions of the female breast. A long-term follow-up study. Cancer 1985;55:2698-708.

30 Vanderbroucke A, Bourdon C. Epidemiological survey of preinvasive breast cancer. Eur f Cancer 1993;2(suppl 3):3prei 10 .

31 Anderson JA. The basement membrane and lobular arcinoma in situ of the breast. Acta Pathol Microbiol Scand 1975;83:245-50.

32 Buerger H, Simon R, Schäfer K-L, et al. Genetic relation of lobular carcinoma in situ, ductal carcinoma in situ, and associated invasive carcinoma of the breast. $f$ Chin Pathol: Mol Pathol 2000;53:118-21. 